\title{
SELF TUNING FUZZY LOGIC CONTROL FOR SRM DRIVEN FROM A SOLAR ENERGY SOURCE
}

\author{
Ahmed Said Oshaba1, 2, Yousry Atia1, 3 and Mohamed Zahran1, 2 \\ 1. Electronics Research Institute, Power Electronics and Energy Conversions \& Photovoltaic Cells \\ Departments \\ NRC Bldg., El-Tahrir St., Dokki, 12311-Giza, Egypt \\ 2. Jizan University, Faculty of Engineering, Electrical Engineering Department, KSA \\ 3. Jizan Technical College, TVTC, Jizan, KSA. \\ oshaba68@hotmail.com,yousry_atia@yahoo.com,mbazahran_2007@yahoo.com
}

\begin{abstract}
This paper presents anadaptive fuzzy logic controller for a switched reluctance motor driven from a photovoltaic supply. The controller is designed to overcome difficulties in SRM operation such as wide speed range, rotor position estimation and photovoltaic nonlinear characteristics. The basic configuration of the fuzzy logic controller (FLC) is introduced and the functions of components are illustrated. The proposed block diagram of the SRM Motor system control under FLC is configured. The system controller manipulated variable as well as the actuators were clearly defined where all the system disturbances are included in the proposed block diagram. The system operation algorithm as well as the FLC algorithm is introduced. The FLC input-variables membership functions as well as the output consequences are illustrated with their universe of discourses. The proposed system is simulated usingMatlab/Simulink and FLC is tested. The simulation results show that the controller is very fast and accurate in tracking the reference speed overall operating conditions.
\end{abstract}

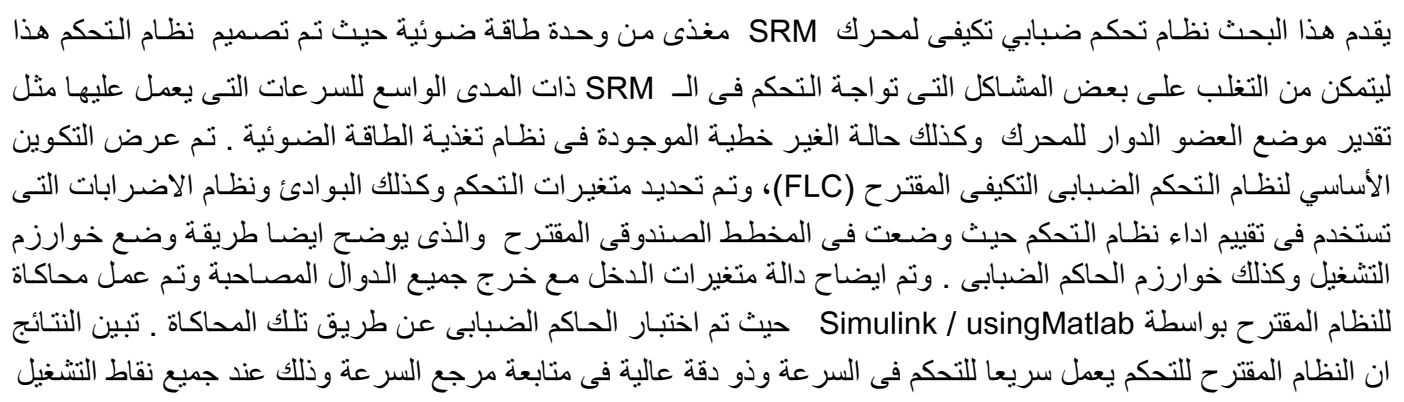

Keywords: SRM,Sensorlessalgorithm, PV system, and Fuzzy logic control. 
required for many variable speed applications especially at high speed ranges. However, lack of information about rotor position, especially at starting, represents a major limiting factor for the wide spread of this type of motors. Shaft position sensors are used to overcome this problem [1-4]. However, it has been observed that such sensing schemes reduce the reliability of the drive system [15-19]. Efforts have been expended on replacing the position sensor with a suitable estimation technique and a number of these algorithms with different degrees of success have already been published [1-4]. Unfortunately most of the existing sensorless schemes do not pay much attention to motor starting although few trials have been reported [5-9].The control of SRM becomes more complicated when the drive system is supplied from a photovoltaic source due to its nonlinear feature especially when maximum power tracing is needed [11-12].

Fuzzy logic control is preferred when the controlled system model is fuzzy and has nonlinear features [13]. Many fuzzy controller designs depend on the controlled variable error and change of error only. However, this is not very effective in stiff nonlinear systems such SRM drive systems which exhibit fast variations in system variables. Subsequently, this paper is considering an alternative design technique for the present SRM system to overcome these difficulties and enhance system performance.

\section{SRM Motor Construction}

The physical appearance of a switched reluctance motor (SRM) highly resembles that of other conventional rotating machines. The number of stator and rotor poles varies from motor to another. The construction of 6/4 poles SRM (6 stator poles, 4 rotor poles) has doubly salient construction. Usually, the number of stator and rotor poles is even and the construction of a $6 / 4$ poles SRM is shown in Fig 1 . The windings of the SRM are simpler than those of other types of motors. The winding exists only on stator poles, and is simply wound on it with no winding on the rotor poles. The winding of opposite poles is connected in series or in parallel forming a number of phases, and exactly half the number of stator poles, where the excitation of a single phase excites two stator poles. The rotor has a simple laminated salient pole structure without winding. SRM have no windings placed on the rotor which means a substantial reduction in copper. Its stampings are made preferably of silicon steel, especially in higher efficiency applications, and for aerospace applications the rotor operates at very high speeds, requiring the use of cobalt, iron and other variants in stator poles fabrication. In conventional designs, the air gap between the rotor and stator is kept as minimal as possible $(0.1 \mathrm{~mm}$ to $0.3 \mathrm{~mm})$, and the rotor and stator pole arc should be kept the same. While in case that the rotor pole arc is larger than the stator pole arc, it will give good starting characteristics. This idea is implemented and tested [1-10].

The construction of 6/4 SRM (stator and rotor) is shown in Fig. (1).

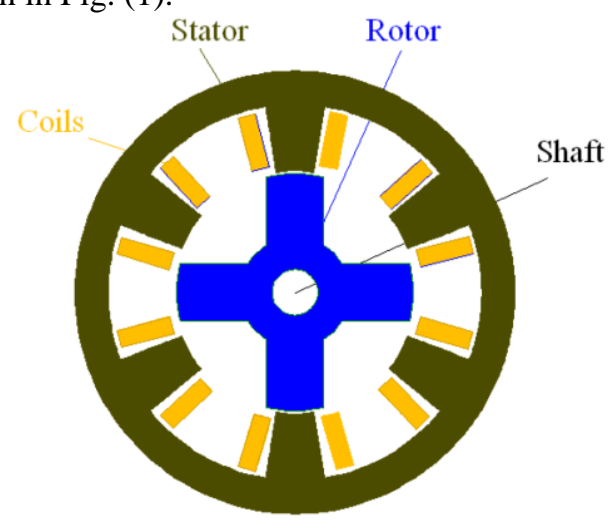

Figure 1: The SRM 6/4 poles construction.

\section{Sensorless Operation of SRM}

The SRM drive depends on the phase current, absolute rotor position, and rotor speed signals to obtain closed-loop control of current (and hence the torque) and speed. Depending on the quality of performance required for a particular application, such as for a low performance, the phase current and speed signals may be dispensed within the control system. The feedback signals are usually measured with transducers, which increase the cost of the electronic controller and its packaging size, reliability and complexity. In the case of a rotor position/speed transducer, the size of the motor housing and the cost are increased significantly. Emerging high-volume applications in heating, ventilation, and air conditioning (HVAC), fans, pumps, home appliances, automobile accessory drives and many others are cost sensitive. The performance requirements for such applications are not high as is required for machine tool servo drives. The requirement of low cost with high performance for motor drives has placed the agenda of low-cost, sensor-based or sensorless technology at the forefront of present day research and development of motor drives. SRM drives are no exception to this trend, as seen from the high degree of interest shown by industrial and academic researchers worldwide on this topic [1-10, 15-27].

\section{Photovoltaic System Powered SRM}

Photovoltaic (PV) power systems convert sunlight into electricity directly. Research and development efforts are underway to improve efficiency and reduce cost of photovoltaic power systems in applications ranging from roof-top residential to large industrial or electrical utility sites. Use of PV power in drive system 
application is increasing these days from direct coupling with the dc motors to sophisticated ac motor drive systems. SRM is one of these motors that need to supply its phases with dc current one phase at a time. The motor is fed via buck boost $\mathrm{dc} / \mathrm{dc}$ converter with a variable duty ratio to extract maximum power from the PV system.

\subsection{PV Generator Characteristics}

The PV cell model is composed of photovoltaic current source $I_{L}$ that is directly proportional with the sunlight intensity (insolation) parallel with a diode and a small series contact resistance as shown in Figure 2. The photovoltaic current characteristics are showninFigure 3 . The output current and voltage from the cell is dependent on the load operating point. The cell equation can be written in the form [11-12]:

$$
\begin{aligned}
& I=I_{L}-I_{D} \\
& I=I_{L}-I_{0}\left(\exp \frac{q\left(V-I R_{S}\right)}{m K T}-1\right) \\
& V=-I R_{S}+\frac{1}{\Lambda} \ln \left(1+\frac{I_{L}-I}{I_{o}}\right) \\
& \text { where: } \Lambda=\frac{q}{m K T}
\end{aligned}
$$

I The cell output current, $\mathrm{V}$ The cell terminal Voltage,

RS Cell series resistance, K Boltzman's

$$
\text { Constant, }
$$

Io The diode reverses saturation current,

T The cell surface absolute temperature,

$\mathbf{Q}$ The electron charge and $m$ the completion Factor.

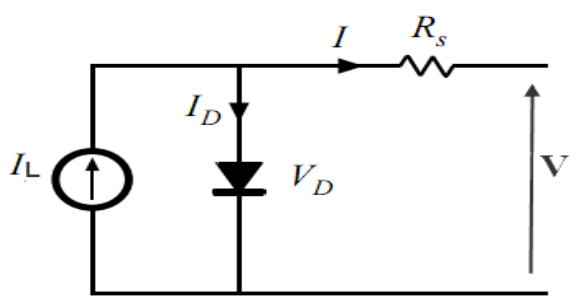

Figure 2: Model of the photovoltaic cell.

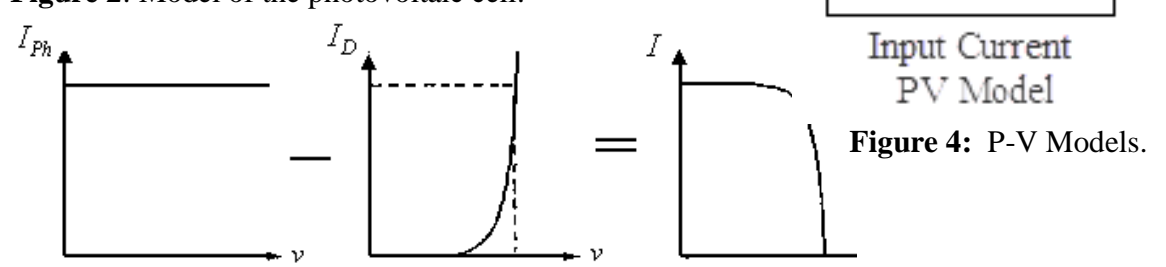

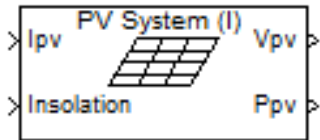

Input Current PV Model

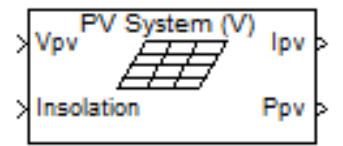

Input Voltage PV Model

Figure 4: P-V system model types

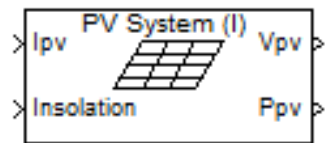

Input Current

PV Todel

igure 4: P-V Models.

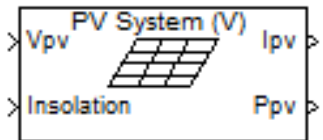

Input Voltage PV Model

Figure 3: Photovoltaic cell characteristics.

For a PV system with NS series cells and NP 


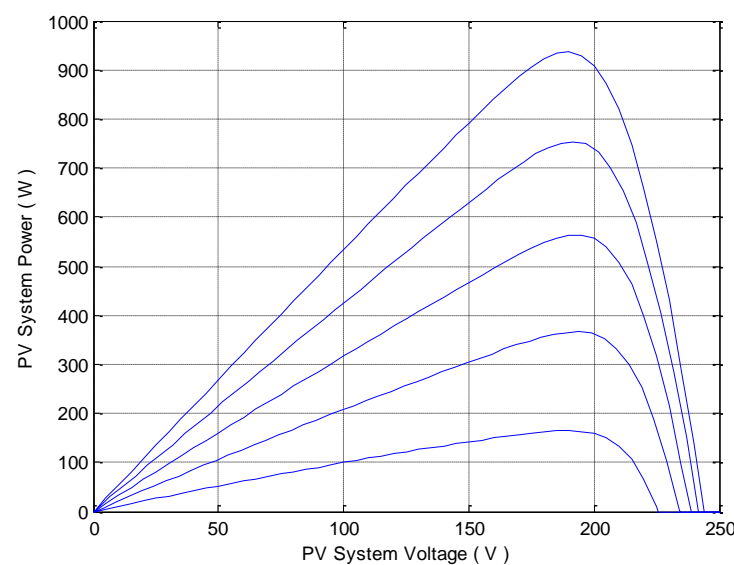

Figure 5: P-V characteristics of the PV system

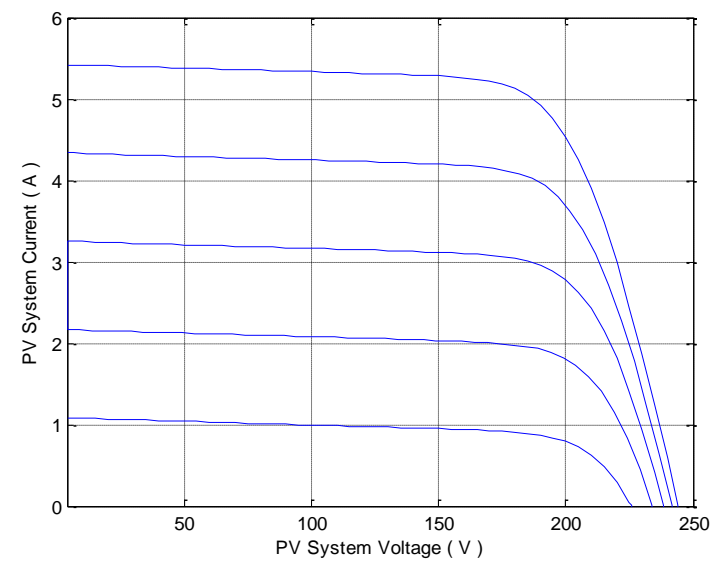

Figure 6: I-V characteristics of the PV system

\section{Control System}

It is known that control strategies for most electrical machines are derived based on machine parameters, which are constant for most of the excitation range. However, due to the salient pole nature of (SRM), the machine inductance is not only a function of the rotor angle but is also a function of the excitation current. This complicates the development of control strategies for such drive systems. The motor nonlinearity renders the search for a control technique suitable for SRM control environments. Subsequently, the concept of control based on the inductance characteristics versus rotor position for a fixed excitation is introduced and is described subsequently [15-27].

\subsection{Fuzzy Sets and Terminology}

Fuzzy logic, unlike the crispy logic in Boolean theory, deals with uncertain or imprecise situations. A variable in fuzzy logic has sets of values, which are characterized by linguistic variables, such as small, medium, large, etc. These linguistic expressions are represented numerically by fuzzy sets (sometimes referred to as fuzzy subsets). Every fuzzy set is characterized by a membership function, which varies from 0 to 1 (unlike 0 and 1 of a Boolean set). Although fuzzy theory deals with imprecise information, it is based on sound quantitative mathematical theory. A fuzzy control algorithm for a process control system embeds the intuition and experience of an operator, designer and researcher. The control does not need accurate mathematical model of a plant and, therefore, it suits well to a process where the model is unknown or ill defined. The fuzzy control also works well for complex nonlinear multi-dimensional system, system with parameter variation problem, or where the sensor signals are not precise. Fuzzy logic is recently finding wide popularity in various applications that include management, economics and process control [13, 15-27].

\subsection{Control Operation}

The inference engine is the heart of a fuzzy controller (and any fuzzy rules system) operation. Its actual operation can be divided into three steps as shown in Figure 7[14]:

1. Fuzzification - actual inputs are fuzzified and fuzzy inputs are obtained.

2. Fuzzy processing - processing fuzzy inputs according to the rules set and producing fuzzy outputs.

3. Defuzzification - producing a crisp real value for a fuzzy output.

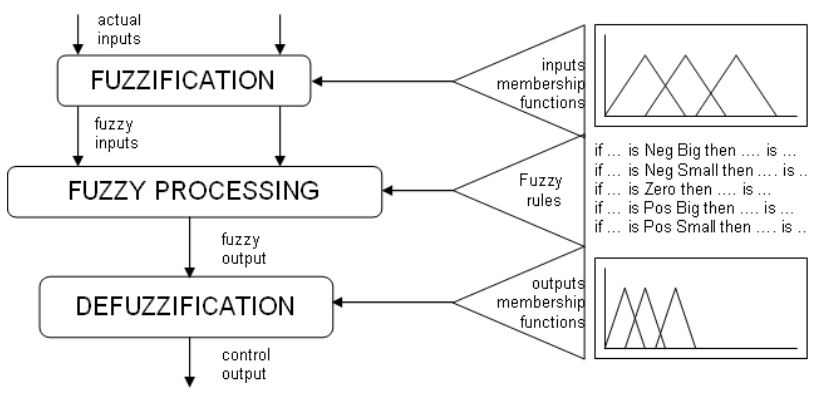

Figure 7: Operation of a fuzzy controller [14].

The success of fuzzy logic controllers is mainly due to their ability to cope with knowledge represented in a linguistic form instead of representation in the conventional mathematical framework. Control engineers have traditionally relied on mathematical models for their designs.

However, the more complex a system, the less effective the mathematical model is. The advantages of using fuzzy logic include the $[10,17]$ : 
Fuzzy controllers are more robust than PID controllers because they can cover a much wider range of operating conditions than PID can, and can operate with noise and disturbances of different natures. Developing a fuzzy controller is cheaper than developing a model-based or other controller to do the same thing.

- Fuzzy controllers are customizable, since it is easier to understand and modify their rules, which not only use a human operator's strategy but also are expressed in natural linguistic terms. It is easy to learn how fuzzy controllers operate, and how to design and apply them to a concrete application.

The basic configuration of a fuzzy system is shown in Figure 8.

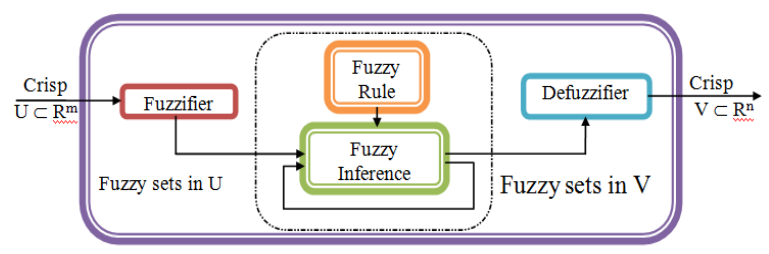

Figure 8: Basic configuration of the fuzzy system.

There are four components in a fuzzy system:

1. Fuzzy rule base which comprises fuzzy rules describing how the fuzzy system performs; it is the heart of the whole system in the sense that other components are used to interpret and combine these rules to form the final system.

2. Fuzzy inference engine which uses techniques in approximate reasoning to determine a mapping from the fuzzy sets in the input space $\mathrm{U} \subset \mathrm{R}^{\mathrm{m}}$ to the fuzzy sets in the output space $\mathrm{V} \subset \mathrm{R}^{\mathrm{n}}$,

3. Fuzzifier which maps crisp points in the input space into fuzzy sets in the input space,

4. Defuzzifier which maps fuzzy sets in the output space into crisp points in the output space.

Depending upon whether there are a Fuzzifier and a Defuzzifier, we have classes of fuzzy systems:

The first class of fuzzy systems comprises only the fuzzy rule base and fuzzy inference engine and, therefore,operates in a pure fuzzy environment, i.e. inputs and outputs to these fuzzy systems are fuzzy variables. If there is a feedback (line connecting the output site to the input one of fuzzy inference engine), we have so called fuzzy dynamic systems.

The second class of fuzzy systems comprises all the four components and performs mapping from crisp $\mathrm{U} \subset \mathrm{R}^{\mathrm{m}}$ to crisp $\mathrm{V} \subset \mathrm{R}^{\mathrm{n}}$. In the literature, these second-class fuzzy systems are called fuzzy logic controllers, because their most successful applications have been to control problems. The fuzzy If-Then rule is an expression of the form "If A Then B", where A and B are statements about what values the linguistic variables take on.

\subsection{Implementation of the FLC}

Three input variables and two fuzzy outputs were used to implement the FLC on this system. The FLC input signals are shown in Figure 9. These are the reference speed value (SP), the error and change of error of actual speed. The Fuzzy interference system acts to predict the desired value of duty cycle of the DC/DC converter "Kd" at the reference speed value (current set point) and the change of control signal of duty cycle "dK" the two output signalsare summed together to form the control signal of DC/DC converter " $\mathrm{K}$ ". The main advantage of this method is the additional $\mathrm{dK}$ signal which acts as a fast tuning value of the control signal. It should be noted that both the desired value $\mathrm{Kd}$ and the change in it $\mathrm{dK}$ are fuzzy output signals included in the fuzzy rules. The dimensions of input signals are $5 * 5 * 5$ which means 125 rules are applied. Figures 9 - 15 showthe membership functions of input and output signals. The universe of discourse of each signal reflects the actual value. It should be noted that error is scaled down by $1 / 200$. The surface viewer of $\mathrm{Kd}$ and $\mathrm{dK}$ at two different reference speeds 20 and $60 \mathrm{Rad} / \mathrm{sec}$ are shown in Figures 16-19.

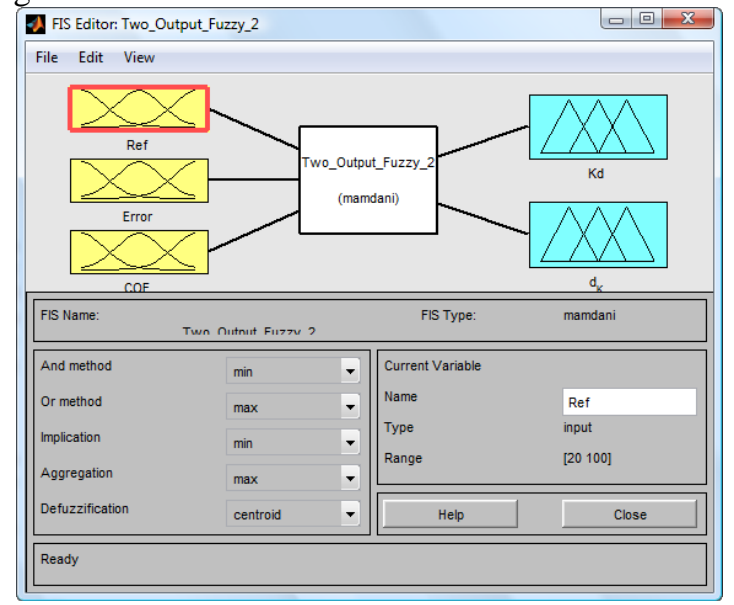

Figure 9: Fuzzy FIS input and outputs; 3 input \& 2 Output. 


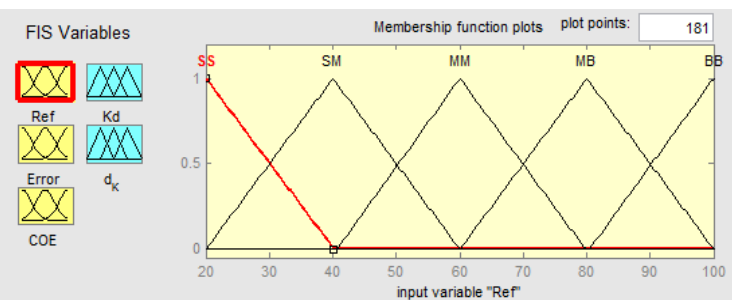

Figure 40: Membership function of input reference values

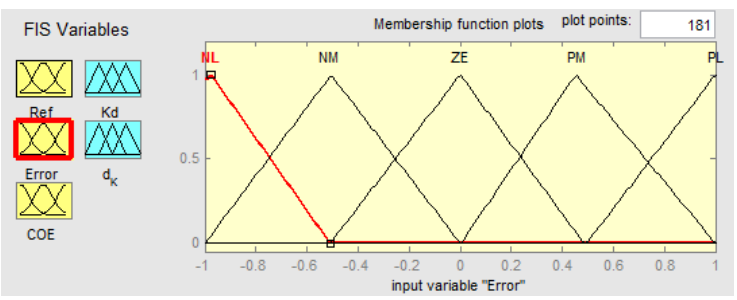

Figure 51: Membership function of input Error

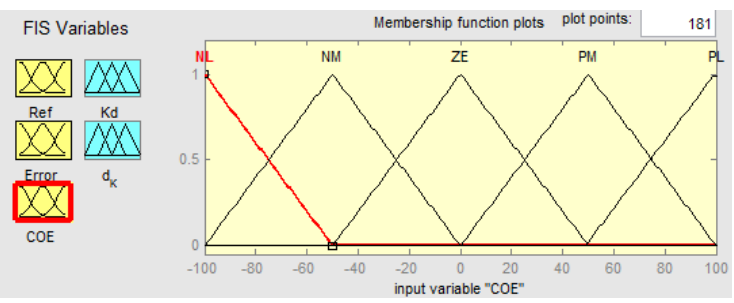

Figure 6: MF of input Change of Error

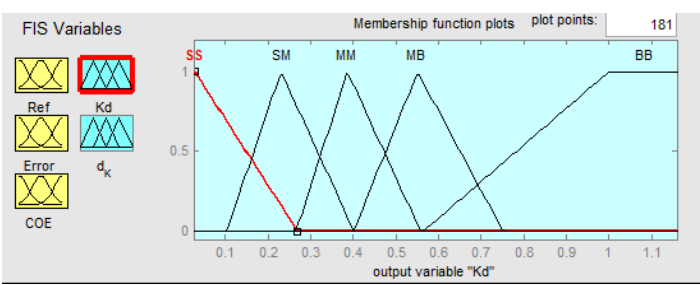

Figure 7: MF of output desired $\mathrm{K}$ value

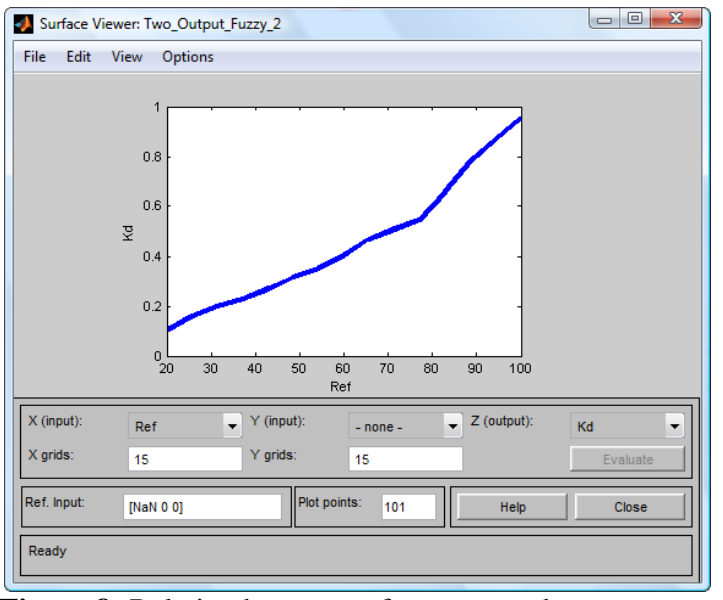

Figure 8: Relation between reference speeds

$(\mathrm{Rad} / \mathrm{sec})$ and desired fuzzy output value

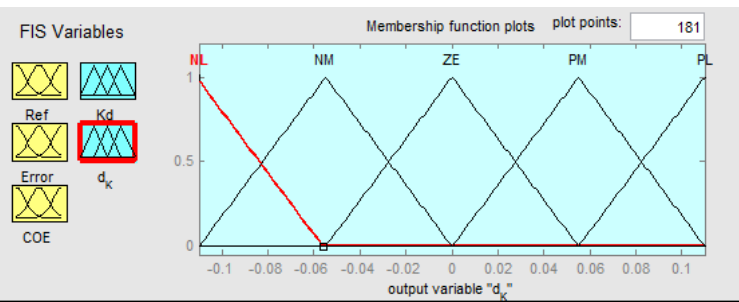

Figure 9: $\mathrm{MF}$ of output change value of $\mathrm{K}$

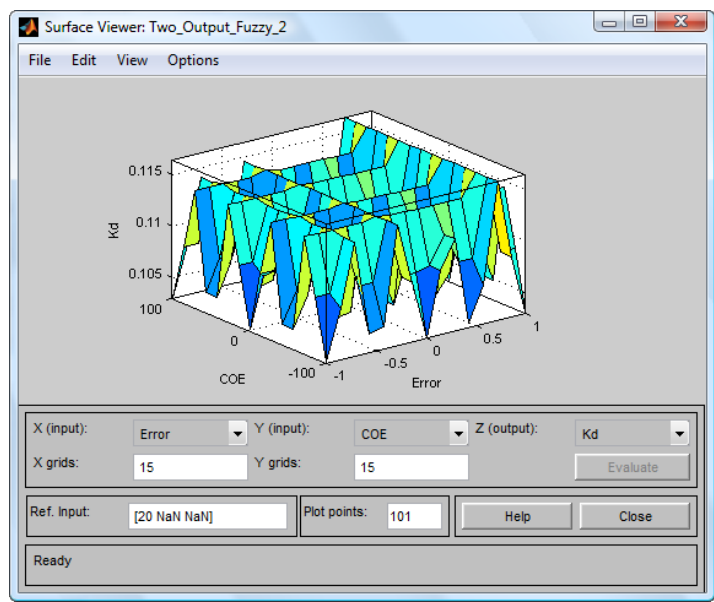

Figure 10: Surface viewer for error, $\mathrm{COE}$ and desired Value of fuzzy output at $20 \mathrm{Rad} / \mathrm{sec}$ Reference value

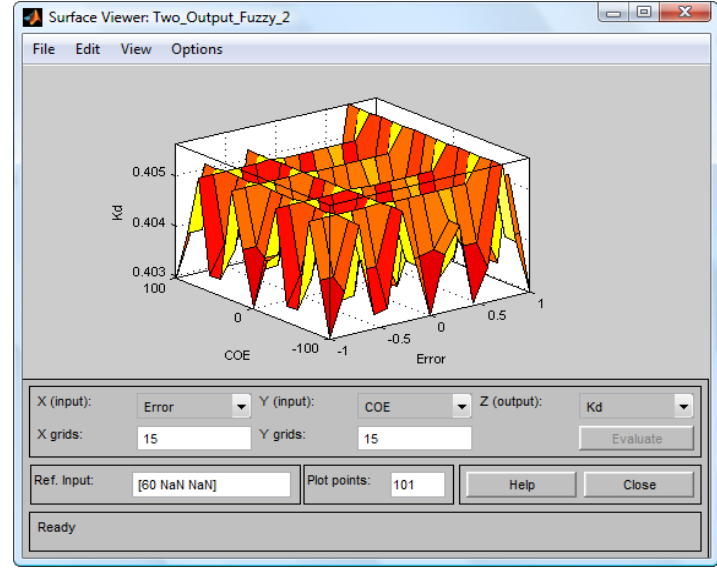

Figure 11: Surface viewer for error, $\mathrm{COE}$ and desired Value of fuzzy output at $60 \mathrm{Rad} / \mathrm{sec}$ Reference value

\section{Modeling of SRM system with PV and FLC}

The SRM system is modeled using MatLab/ Simulink. The following figure shows the SRM system. An advanced self-tuned fuzzy logic controller system is implemented. As mentioned in section 6.1, the three input variables of FLC are reference speed, error and change of error of actual speed. The two fuzzy output signalsarecomposed ofthe duty cycle of DC/DC converter to generate the desired voltage relevant for the desired speed. 


\section{Proposed System Configuration}

The proposed system is composed of the PV array with controlled DC/DC buck boost converter, connected directly to the SRM. The motor model is fed from the PV system via the DC/DC converter. The motor model outs two variables for control; the motor required current, and the motor speed plus the required signals for monitoring

The actual motor speed is compared with the reference speed to give us the speed error. With a delay block we can obtain the rate of error change. Then the fuzzy logic controller according to the reference speed, speed error and change of speed error gives us the required duty ratio for the DC/DC converter that is included in the PV system block. The block diagram of the proposed system is shown in Figure 20.

The system is applied to variable speed commands as shown in the results section and the reference and actual speed are recorded.

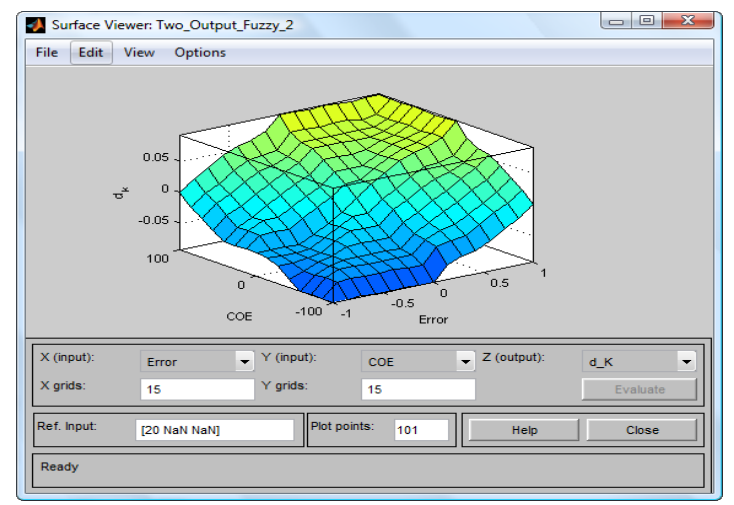

Figure 18: Surface viewer for error, $\mathrm{COE}$ and change $\mathrm{K}$ of fuzzy output at $20 \mathrm{Rad} / \mathrm{sec}$ reference Value .

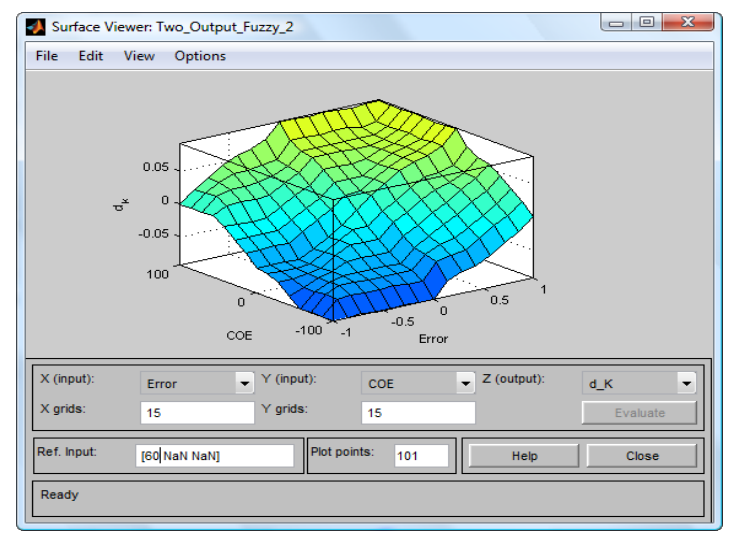

Figure 19: Surface viewer for error, $\mathrm{COE}$ and change $\mathrm{K}$ of fuzzy output at $60 \mathrm{Rad} / \mathrm{sec}$ reference Value.

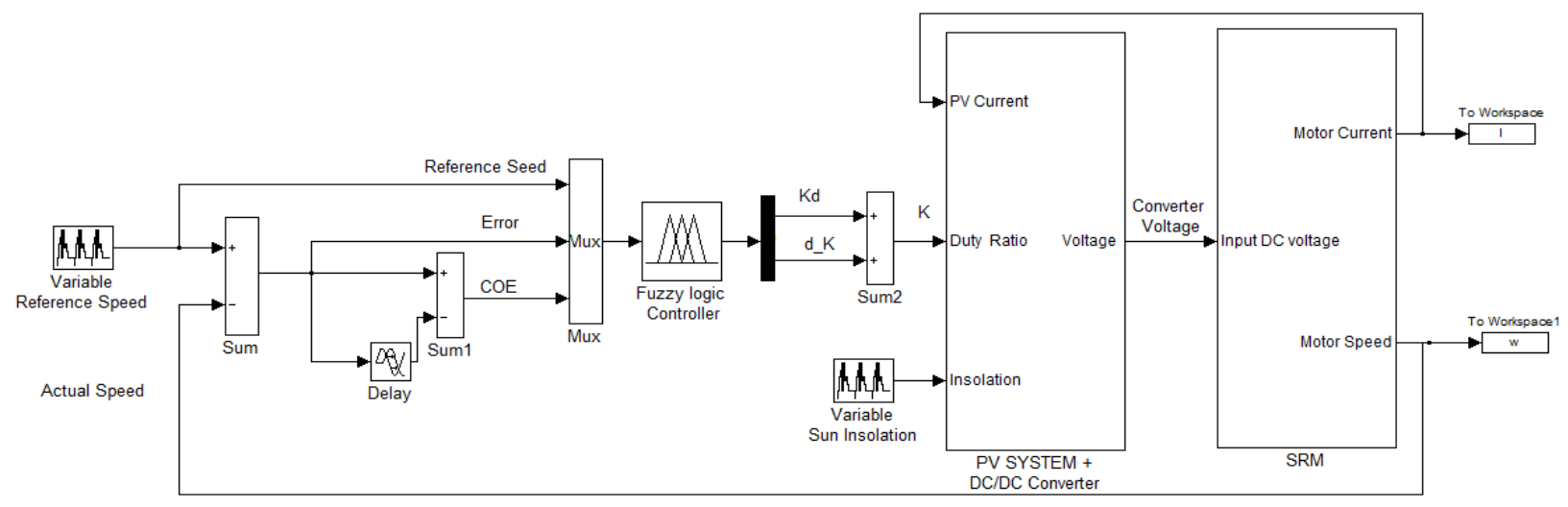

Figure 12: Block diagram of the proposed speed controlled SRM. 


\section{Simulation Results}

The system is subjected to severe step changes in reference speed over a period of $15 \mathrm{sec}$ and the results are shown in Figure 13. The actual speed variesfrom 0 to 1000 RPM and the proposed starting method is used. This result clearly shows that the actual motor speed tracks the reference speed smoothly over the whole operating range without hesitation at starting or steady state error which substantiates the effectiveness of the proposed controller. Figure 23: The three phase instantaneous stator current at The full speed.

and 23illustrate the three phases stator current and that the angle between phases is $30^{\circ}$. The dwell angle (difference between Toff and Ton angle) is kept fixed and each phase and the pulse train is phase shifted by:

$$
\text { (30* } \left.C_{r}-T_{\text {on }}=22.5^{\circ}\right) \text {. }
$$

The three phase instantaneous torque of the motor is shown in Figure 15and the three phases instantaneous inductance is shown in Figure 16. These curves are used to obtain the inductance from unaligned position to aligned position Figure 17 illustrates the drive phase voltage/150, stator phase current/2 and stator phase flux linkage.

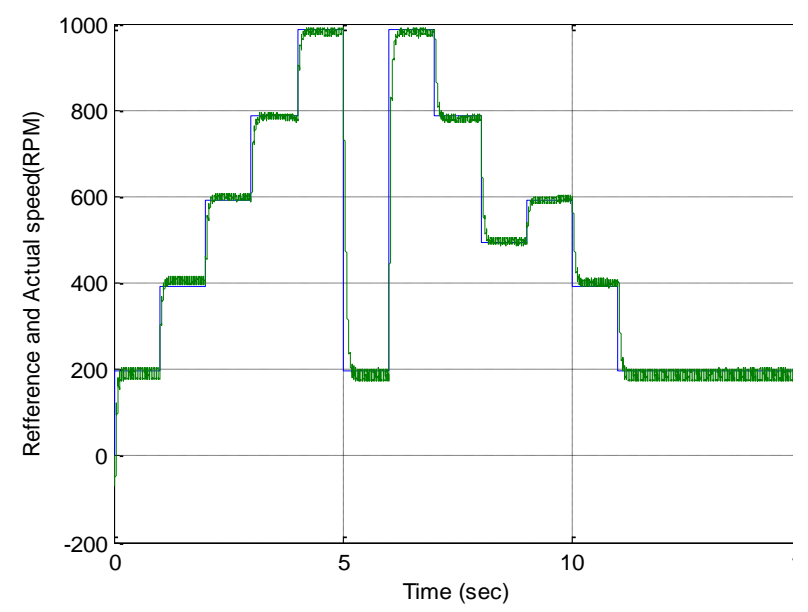

Figure 13: Response to step changes in reference speed.

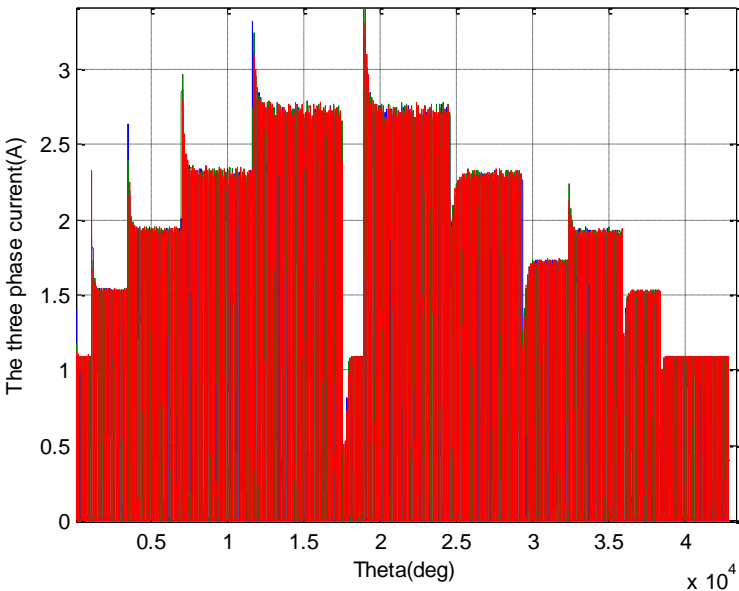

Figure 14: The three phase instantaneous stator current.

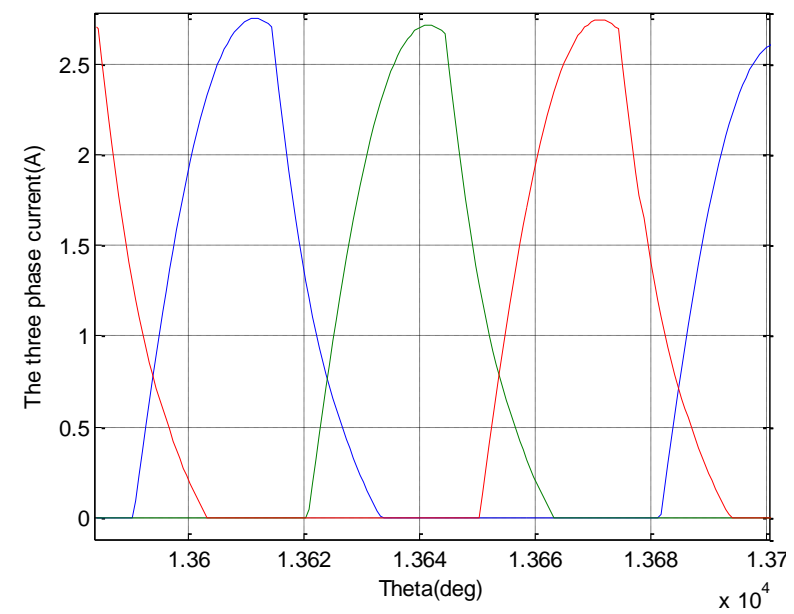

Figure 23: The three phase instantaneous stator current at The full speed.

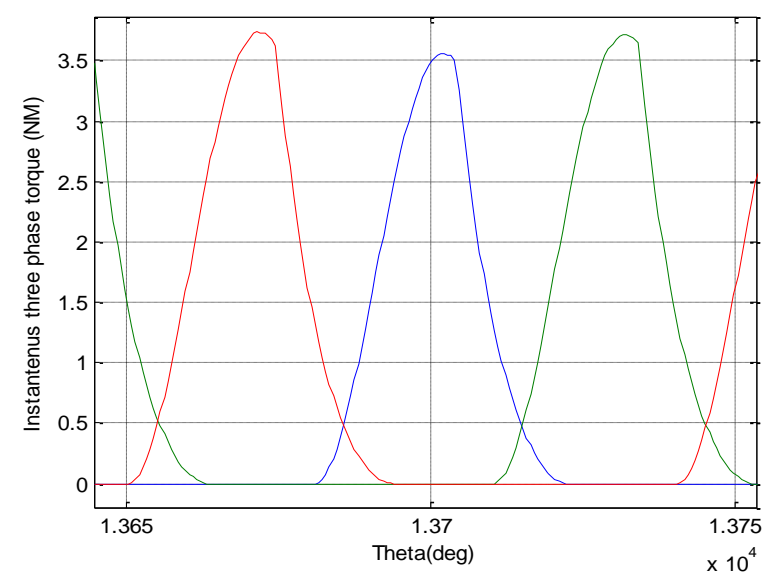

Figure 15: The three phase instantaneous motor torque at the full speed. 


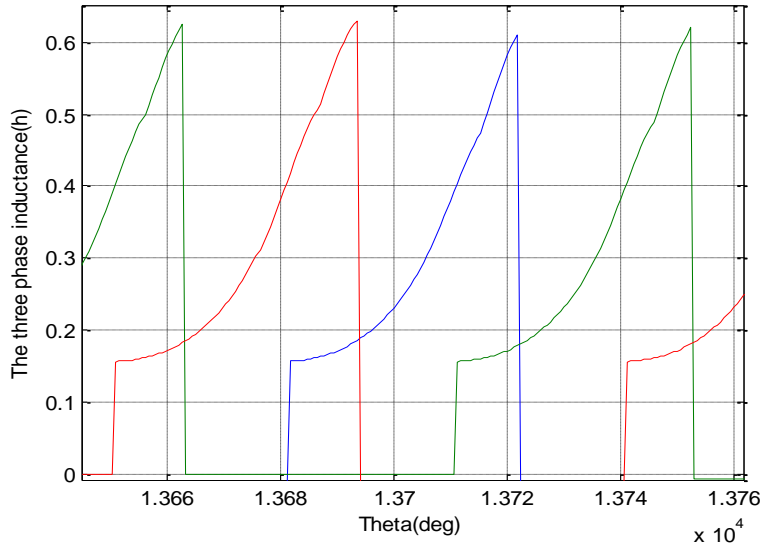

Figure 16: The three phase instantaneous stator inductance at the full speed.

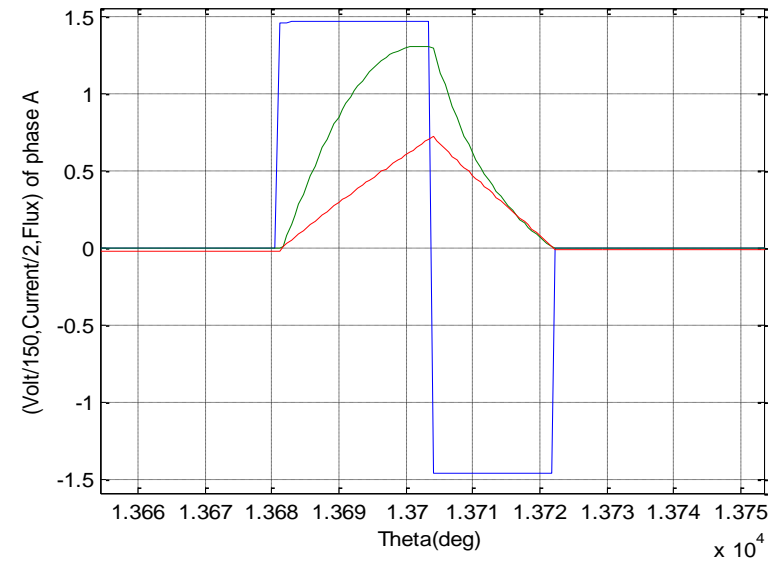

Figure 17: The phase voltage/150 (Blue), phase current/2(Green) and phase flux (Red)

\section{Conclusions}

This paper described the design and implementation of an adaptive fuzzy logic control for SRN drive system fed from solar supply. An accurate sensorless speed control technique for SRM (6/4 poles) (three phases) model considering the nonlinear analyses is used. A simulation model was developed using Matlab/Simulink. The motor simulation depends on the experimental work for (flux linkage - current) look-up table and static torque look-up table, where an interpolation method is used for estimation of the motor characteristics (I, Tdev) from two lock-up table. It has been clearly shown that the position estimation method for SRM is reliable and copes effectively over the whole operating range. The motor starts normally with no hesitation and the controller is also very efficient when step changes occur. It has been shown that the developed adaptive fuzzy logic controller works effectively to adjust the duty ratio for the DC/DC converter. The results presented in the paper are of prime importance to overcome difficulties in SRM operation which enables the wide spread applications of SRM in variable speed drive systems.

\section{References}

[1] Dan Jones,"Present and future applications of switched reluctance motor and drive", SMIC'99 conference, October 1999, Tokyo, Japan.

[2] J.M. Stephenson and J. Corda "Computation of Torque Current in Double Salient Reluctance Motors From Nonlinear Magnetization Data" proceedings IEE,vol.126, No.5,May 1979, pp. 393-396.

[3] J. Corda and J.M. Stephenson "Analytical Estimation of the Minimum and Maximum Inductances of a Double-Salient Motor" Proceedings of the International Conference on Stepping Motors and Systems, University of Leeds, UK, September 1979, pp. 50-59.

[4] Shuyu Cao, and K.J. Teseng, “A New Method for Accurate Analytical Modeling of Switched Reluctance Motor" PEDES'98 Vol. II, December 1998 pp.540-545.

[5] P.J. Lawrenson and J.M. Stephenson "Variable-Speed Switched Reluctance Motors" IEE Proc. Vol. 127, Pt. B. No. 4, July 1980, pp. 253-265.

[6] C. Rochford, R.C. Kavanagh, M.G. Egan and J.M.D. Murphy "Development of Smooth Torque in Switched Reluctance Motors Using Self-Learning Techniques" ENE'93, pp. 14-19.

[7] J.J. Gribble P.C. Kjaer and T.J.E. Miller "Optimal Commutation in Average Torque Control of Switched Reluctance Motors" IEE Proc.-Electric Power Appl., vol. 146, No. 1, January 1999, pp. 2-10.

[8] Khwaja M. Rahman, Suresh Gopalakrishnan, BabakFahimi,

AnandanVelayuthamRajarathnam and M. Ehsani "Optimized Torque Control of Switched Reluctance Motor at All Operational Regimes Using Neural Network" IEEE Transations on Industry Applications, vol. 37, NO. 3, May/June 2001, pp. 904-913.

[9] Krzysztof Russa, Iqbal Husain and Malik E. Elbuluk "A Self-Tuning Controller for Switched Reluctance Motors" IEEE Transactions on power electronics, vol. [10] Ahmed Oshaba, "Analysis and Control of SRM", Ph.D. Thesis, Cairo Univ., FOE, April, 2004. 
[11] YousryAtia, "Photovoltaic Maximum Power Point Tracking Using SEPIC Converter", Engineering Research Journal (ERJ), Shebin El-Kom Journal, Vol.36, No.4, October 2009.

[12]E. Matagne, Chenni R, El Bachtiri R., "A photovoltaic cell model based on nominal data only", International Conference on Power Engineering, Energy and Electrical Drives, 2007. Powereng 2007. 12-14 April 2007 Setubal, Portugal.

[13] M. Zahran, A. Hanafy, 0. Mahgoub and M. Kamel, "FLC Based Photovoltaic Battery Diesel Hybrid System Management and Control", 28th IEEE Photovoltaic Specialists Conference", September 15-22,2000, Anchorage, Alaska, USA, 0-7803-5772-( 2000 IEEE

[14] AykutKentli, "Studies On Fuzzy Logic Control Of Electrical Machines In Turkish Universities: An Overview", Mathematical and Computational Applications, Vol. 16, No. 1, pp. 236-247, 2011.

[15] Chen H. \&Gu J. J. (2010). Implementation of the Three-Phase Switched Reluctance Machine System for Motors and Generators. IEEE/ASME Transactions on Mechatronics, Vol.15, No.3, June 2010, 421-432, ISSN 1083-4435.

[16] Naayagi R. T. \&Kamaraj V. (2005). Shape Optimization of Switched Reluctance Machine for Aerospace Applications, Proceedings of 31st Annual conference of IEEE Industrial Electronics Society, pp. 1748-1751, ISBN 0-7803-9252-3, Raleigh, November 2005, IEEE Industrial Electronics Society, Los Alamitos.

[17] Liu W. \& Song S. (2006). Application of Fuzzy Control in Switched Reluctance Motor Speed Regulating System, Proceedings of International Conference on Computational Intelligence for Modelling, Control and Automation, pp. 72-72, ISBN 0-7695-2731-0, Sydney, November 2006, Patrick Kellenberger, Sydney.

[18] K. M. Rahman, B. Fahimi, G. Suresh, A. V. Rajarathnam, and M. Ehsani, "Advantages of switched reluctance motor applications to EV and HEV: Design and control issues," IEEE Trans. Ind. Appl., vol. 36, no. 1, pp. 111-121, Jan./Feb. 2000.
[19] K. M. Rahman and S. E. Schulz, "Design of high efficiency and high density switched reluctance motor for vehicle propulsion," IEEE Trans. Ind. Appl., vol. 38, no. 6, pp. 1500-1507, Nov./Dec. 2002.

[20] T. J. E. Miller, "Optimal design of switched reluctance motors," IEEE Trans. Ind. Electron., vol. 49, no. 1, pp. 15-27, Feb. 2002.

[21] R. B. Inderka, M. Menne, and R. W. A. A. De Doncker, "Control of switched reluctance drives for electric vehicle applications," IEEE Trans.Ind. Electron., vol. 49, no. 1, pp. 48-53, Feb. 2002.

[22] Husain and S. A. Hossain, "Modeling, simulation, and control of switched reluctance motor drives," IEEE Trans. Ind. Electron., vol. 52, no. 6, pp. 1625-1634, Dec. 2005.

[23] K. Jain and N. Mohan, "Dynamic modeling, experimental characterization, and verification for SRM operation with simultaneous two-phase excitation,” IEEE Trans. Ind. Electron., vol. 53, no. 4, pp. 1238-1249, Jun. 2006.

[24] Jae-Hak Choi, Joonseon S. Ahn and Ju Lee, "The Characteristic Analysis of Switched Reluctance Motor Considering DC-Link Voltage Ripple on Hard and Soft Chopping Modes," IEEE transactions on magnetics, Vol. 41, No.10, pp. 4096-4098, Oct. 2005.

[25] X. D. Xue, K. W. E. Cheng, and S. L. Ho, “A position stepping method for predicting performances of switched reluctance motor drives," IEEE Trans. Energy Convers., vol. 22, no. 4, pp. 839-847, Dec. 2007.

[26] J. G. Amoros and P. Andrada, "Sensitivity analysis of geometrical parameters on a double-sided linear switched reluctance motor," IEEE Trans. Ind. Electron., vol. 57, no. 1, pp. 311-319, Jan. 2010.

[27]R. Krishnan, Switched Reluctance Motor Drives-Modeling, Simulation, Analysis, Design, and Applications. Boca Raton, FL: CRC Press, 2001. 